\title{
Optimasi Query Hash Join Dan Inner Join Pada Sistem Pencarian Data Tracer Study (Optimization Of Query Hash Join And Inner Join In Tracer Study Data Search System)
}

\author{
Moh. Erkamim¹), Farid Fitriyadi22, Ikhwan Baidlowi Sumafta3) \\ 1)3)Sistem Informasi Kota Cerdas, Fakultas Teknik, Universitas Tunas Pembangunan Surakarta \\ 2)Informatika, Fakultas Teknik, Universitas Sahid Surakarta \\ E-mail: 1)erkamim@lecture.utp.ac.id, 2)faridfitriyadi@gmail.com, ${ }^{3)}$ ibsumafta@lecture.utp.ac.id
}

\begin{abstract}
Abstrak
Optimasi query merupakana solusi dalam permasalahan kompleknya query yang kita buat guna menghasilkan data dengan kondisi tertentu, optimasi query memberikan sebuah model pemecahan masalah dengan menggabungkan teknik-teknik yang meliputi transformasi logika serta mempresentasikan teknik tersebut dalam sebuah masalah. Semua model query yang menghasilkan (output) yang sama tetapi waktu proses yang berbedabeda. Pemecahan masalah dengan membandingkan dua bentuk algoritma yang paling banyak digunakan merupakan salah satu yang menjadi pertimbangan peneliti untuk mengetahui mana yang terbaik yang dapat digunakan pada kondisi tertentu. Hash join dan Inner join query merupakan query yang termasuk banyak digunakan untuk sebuah rancang bangun basis data. Masalah paling penting adalah bagaimana menentukan query dengan akses tercepat dari query tersebut pada sebuah basis sistem tertentu, sehingga menjadikan judul ini sebagai pertimbangan dari penulis untuk melakukan optimasi query pencarian data alumni dengan Hash Join query.
\end{abstract}

Kata Kunci-Optimasi, Tracer Study, Query, Hash Join, Inner Join

Abstract

Query optimization a solution to the complex problem of queries that we make to produce data with certain conditions, query optimization provides a problem solving model by combining techniques that include logical transformations and presenting these techniques in a problem. All query models that produce (output) the same but different processing times. Problem solving by comparing the two forms of the most widely used algorithm is one of the considerations for researchers to find out which one is the best that can be used in certain conditions. Hash join and Inner join query are queries that are widely used for database design. The most important problem is how to determine the query with the fastest access from the query on a certain basis system, so that this title is considered by the author to optimize the alumni data search query with Hash Join queries.

Keywords - Optimization, Tracer Study, Query, Hash Join, Inner Join

\section{Pendahuluan}

Query merupakan suatu perintah untuk melakukan pengolahan data dari database dimana dapat memanggil tabel-tabel yang ada pada database tersebut, namun tabel tersebut tidak semua ditampilkan, hanya sesuai data yang diinginkan atau data yang ingin ditampilkan [1]. Join table merupakan gabungan beberapa tabel menggunakan Query yang dilakukan pada kolom key yang memiliki nilai terkait untuk mendapatkan satu set data dengan informasi lengkap [2]. Join diperlukan karena perancangan tabel pada sistem transaksional kebanyakan dinormalisasi, salah satu alasannya untuk mengurangi redundansi[3]. Pencarian data dengan menggunakan Query atau Join pada database perlu memperhatikan ketepatgunaan implementasi dari data itu sendiri serta waktu prosesnya [3]. Banyak model menemukan sebuah query, meskipun banyak query yang dapat digunakan dalam sebuah kasus dalam pengolahan database, misalnya query yang digunakan untuk pencarian data, akan menghasilkan output yang sama, namun dengan proses yang berbeda tergantung bagaimana struktur dan banyaknya record dalam database tersebut [4]. Dari semua query yang dapat digunakan, khususnya query yang digunakan untuk pencarian data, sangat diperhatikan waktu kecepatan akses yang diperlukan untuk mencari sebuah data, query mana saja yang memiliki akses lebih cepat untuk mendapatkan sebuah nilai, khususnya untuk record data yang besar. hash join query memiliki fungsi untuk efisiensi dalam database management system [5]. 
Permasalahan pada penelitian ini ialah, penulis ingin mencari query untuk pencarian data dengan akses data yang lebih cepat dengan penggunaan waktu yang lebih minimum dengan model hash join query dengan menggunakan database sistem tracer study yang ada pada Universitas Tunas Pembangunan [6]. Dari permasalahan di atas menjadi alasan penulis untuk melakukan penelitian dengan judul "Optimasi Query Hash Join Dan Inner Join Pada Sistem Pencarian Data Tracer Study".

\section{Metode Penelitian}

Action research atau penelitian tindakan dilakukan dengan membuat sistematik yang terfokus pada penyempurnaan proses atau perbaikan teknik dalam menjalankan query yang sudah digunakan dengan membuat pembandingan antara query hash join dan inner join dari sisi kecepatan dalam mengelola record data.

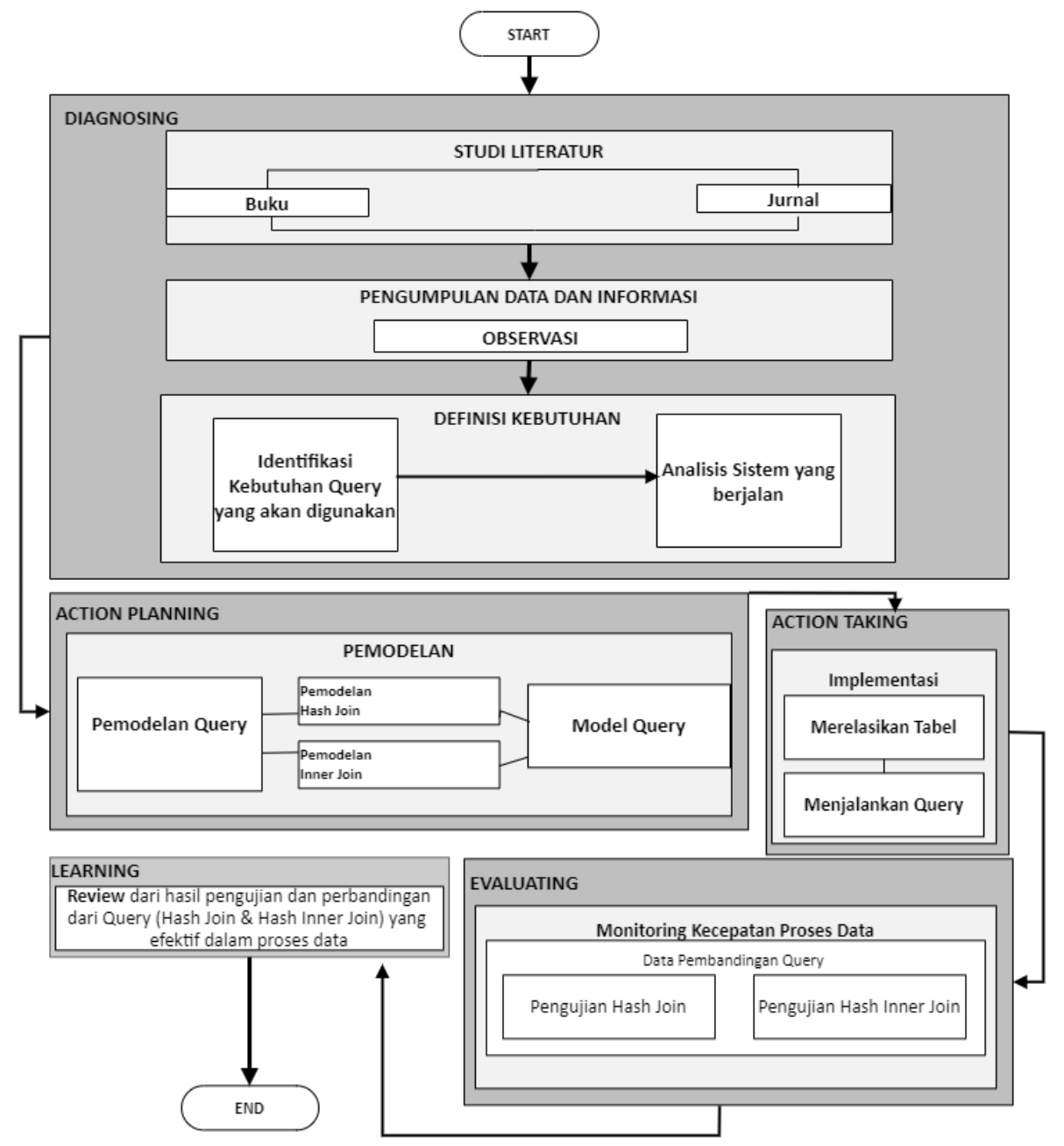

Gambar 1. Alur Penelitian

\section{a. Melakukan diagnosa (diagnosing)}

Identifikasi masalah pokok yang digunakan dasar optimasi query yang akan digunakan dalam ujicoba pembandingan optimasi.

\section{b. Membuat rencana tindakan (action planning)}

Menentukan model query yang akan digunakan dalam memperoleh informasi dari sisi kecepatan dalam mengelola record. 


\section{c. Melakukan tindakan (action taking)}

Mengimplementasikan model query hash join dan inner join serta melakukan ujicoba dalam merelasikan data maupun tabel.

\section{d. Melakukan evaluasi (evaluating)}

Setelah implementasi (action taking) dilanjutkan dengan evaluasi hasil dari implementasi untuk mengetahui perbandingan dari kedua model query yang digunakan.

\section{e. Pembelajaran (learning)}

Mengetahui informasi model query dari sisi kecepatan dalam mengelola record.

\section{Hasil dan Pembahasan}

Penelitian ini untuk mengetahui kinerja optimalisasi query hash join dan inner join dilakukan dengan mengevaluasi hasil kinerja query berdasarakan kecepatan proses. Adapun hasil dalam pengujian optimalisasi kinerja kecepatan query ditampilkan pada tabel-tabel hasil record sebagi berikut

\section{a. Hasil perbandingan waktu proses kinerja query}

Hasil ujicoba kinerja query hash join dengan inner join menghasilkan kinerja query dari sisi kecepatan dengan 1 sampai 3 relasi, adapun hasil kinerja ini sebagai berikut.

1) Hasil perbandingan waktu akses query satu relasi

Hasil ujicoba kinerja query hash join dengan inner join satu relasi dalam hal perbandingan waktu terdapat selisih hasil pemprosesan query.

Tabel 1. Kinerja query hash join dengan inner join satu relasi

\begin{tabular}{cccc}
\hline \multirow{2}{*}{ No } & \multirow{2}{*}{ Jumlah Data/Record } & \multicolumn{2}{c}{ Waktu (second/detik) } \\
\cline { 3 - 4 } & 166 & Hash Join & Inner Join \\
\hline 1 & 322 & 0.0015 & 0.00015 \\
\hline 2 & 0.0022 & 0.00028 \\
\hline
\end{tabular}

2) Hasil perbandingan waktu akses query dua relasi

Hasil ujicoba kinerja query hash join dengan inner join dua relasi dalam hal perbandingan waktu terdapat selisih hasil pemprosesan query.

Tabel 2. Kinerja query hash join dengan inner join satu relasi

\begin{tabular}{cccc}
\hline \multirow{2}{*}{ No } & \multirow{2}{*}{ Jumlah Data/Record } & \multicolumn{2}{c}{ Waktu (second/detik) } \\
\cline { 3 - 4 } & 166 & Hash Join & Inner Join \\
\hline 1 & 322 & 0.0018 & 0.00020 \\
\hline 2 & 0.0030 & 0.00033 \\
\hline
\end{tabular}

3) Hasil perbandingan waktu akses query tiga relasi

Hasil ujicoba kinerja query hash join dengan inner join tiga relasi dalam hal perbandingan waktu terdapat selisih hasil pemprosesan query.

Tabel 3. Kinerja query hash join dengan inner join satu relasi

\begin{tabular}{cccc}
\hline \multirow{2}{*}{ No } & \multirow{2}{*}{ Jumlah Data/Record } & \multicolumn{2}{c}{ Waktu (second/detik) } \\
\cline { 3 - 4 } & 166 & Hash Join & Inner Join \\
\hline 1 & 322 & 0.0027 & 0.00029 \\
\hline 2 & 0.0032 & 0.00041 \\
\hline
\end{tabular}




\section{b. Pembahasan}

Pada tahap ini memerlukan identifikasi berupa perancangan data yang akan dilakukan ujicoba mulai dari rancangan database sampai dengan query pada record terntentu yang telah ditentukan untuk mengetahui perbandingan penggunaan teknik query hash join dengan inner join adapun proses dalam proses penelitian ini dengan pengujian pada kasus data yang sudah kita sediakan adapun proses sebagai berikut.

1) Rancangan Database

Merupakan data tabel yang disediakan untuk melakukan ujicoba langsung terhadap kinerja masing-masing query, adapun database tersebut sebagai berikut.

Tabel 4. Tabel User

\begin{tabular}{|c|c|c|}
\hline Nama Field & Type & Ukuran \\
\hline user id & int & 10 \\
\hline username & varchar & 10 \\
\hline password & varchar & 50 \\
\hline level & enum & - \\
\hline aktif & enum & - \\
\hline date_create & timestamp & - \\
\hline enc & varchar & 50 \\
\hline
\end{tabular}

Tabel 5. Tabel Biodata

\begin{tabular}{|c|c|c|}
\hline Nama Field & Type & Ukuran \\
\hline biodata id & int & 10 \\
\hline id_user & int & 10 \\
\hline nim & varchar & 10 \\
\hline nama & varchar & 50 \\
\hline id_prodi & int & 1 \\
\hline tempat_lahir & varchar & 50 \\
\hline tanggal_lahir & date & - \\
\hline jenis_kelamin & enum & - \\
\hline agama & enum & - \\
\hline warga_negara & varchar & 30 \\
\hline alamat & varchar & 100 \\
\hline tlpn & varchar & 15 \\
\hline email & varchar & 50 \\
\hline tahun_lulus & date & \\
\hline foto & varchar & 40 \\
\hline ipk & decimal & 3.2 \\
\hline skripsi & text & \\
\hline status_kerja & varchar & 10 \\
\hline tempat_kerja & varchar & 50 \\
\hline tahun_wisuda & varchar & 4 \\
\hline
\end{tabular}


Tabel 6. Tabel Keluarga

\begin{tabular}{|c|c|c|}
\hline Nama Field & Type & Ukuran \\
\hline keluarga_id & int & 10 \\
\hline nama_ayah & varchar & 50 \\
\hline nama_ibu & varchar & 50 \\
\hline alamat_keluarga & varchar & 100 \\
\hline tlpn_keluarga & varchar & 15 \\
\hline id_user & Int & 10 \\
\hline
\end{tabular}

Tabel 7. Tabel Fakultas

\begin{tabular}{lrrr}
\hline & & Type & Ukuran \\
\hline fakultas kode & varchar & 10 \\
\hline fakultas & varchar & 50 \\
\hline
\end{tabular}

Tabel 8. Tabel Prodi

\begin{tabular}{|c|c|c|}
\hline Nama Field & Type & Ukuran \\
\hline prodi_id & int & 2 \\
\hline prodi & varchar & 50 \\
\hline prodi_kode & varchar & 10 \\
\hline kode_fakultas & varchar & 10 \\
\hline
\end{tabular}

2) Query Algoritma

Pengujian pencarian data menggunakan query dua algoritma yaitu Natural Join dan Hash Join. Pengujian Query dalam hal pencarian data berdasarkan banyak jumlah data untuk melakukan pencarian data dibagi atas beberapa tahap relasi. Pengujian aplikasi ini menggunakan phpmyadmin sql sebagai server penyimpanan database. Pengujian kinerja query Algoritma dalam pencarian data dari sebuah aplikasi maka query dibagi berdasarkan jumlah tabel yang saling berhubungan.

a) Query 1 Relasi

Menggunakan 2 (dua) tabel yaitu tabel user dan biodata yang saling berhubungan antar tabel.

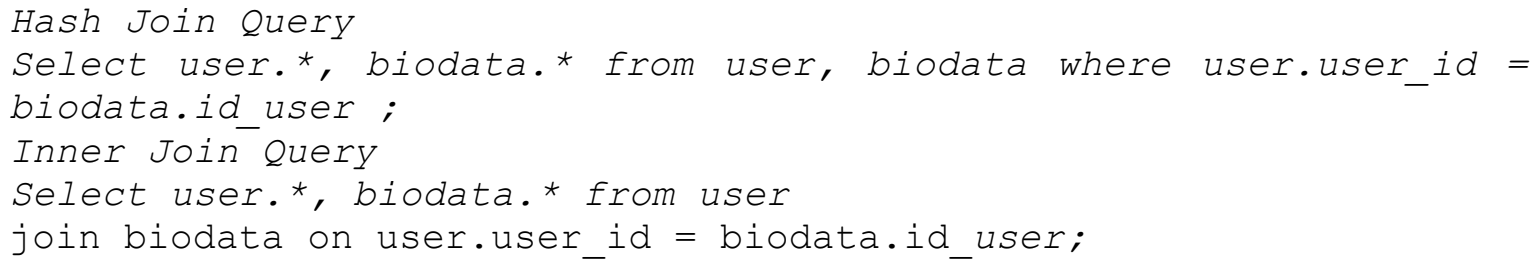

b) Query 2 Relasi

Menggunakan 3 (tiga) tabel yaitu tabel user, biodata, keluarga yang saling berhubungan antar tabel.

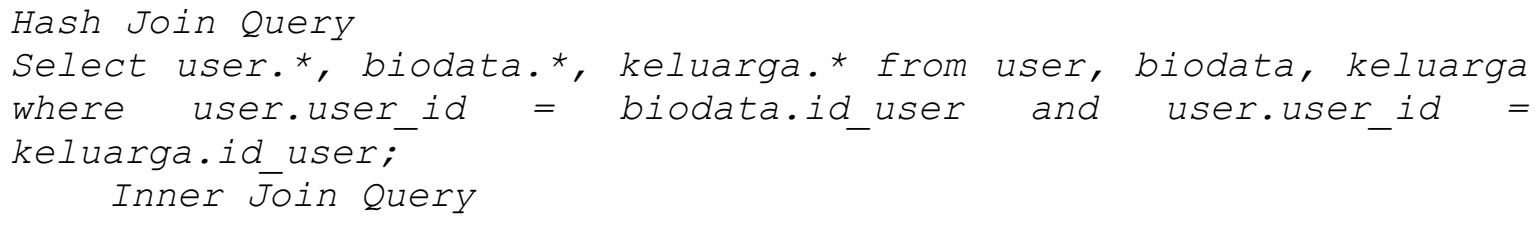


Select user.*, biodata.*, keluarga. * from user join biodata on user.user_id = biodata.id_user join keluarga on user.user_id= keluarga.ìduser;

c) Query 3 Relasi

Menggunakan 4 (empat) tabel yaitu tabel user, biodata, keluarga dan prodi yang saling berhubungan antar tabel.

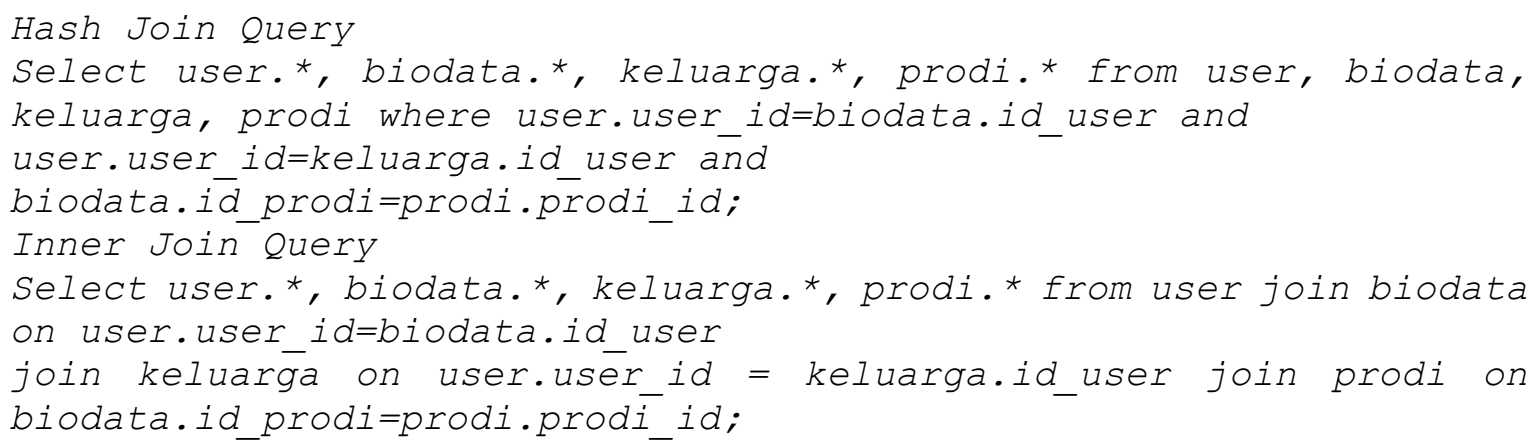

3) Hasil Pengujian Query

a) Query 1 Relasi

Menggunakan 2 (dua) tabel yaitu tabel user dan biodata yang saling berhubungan antar tabel Hash Join Query

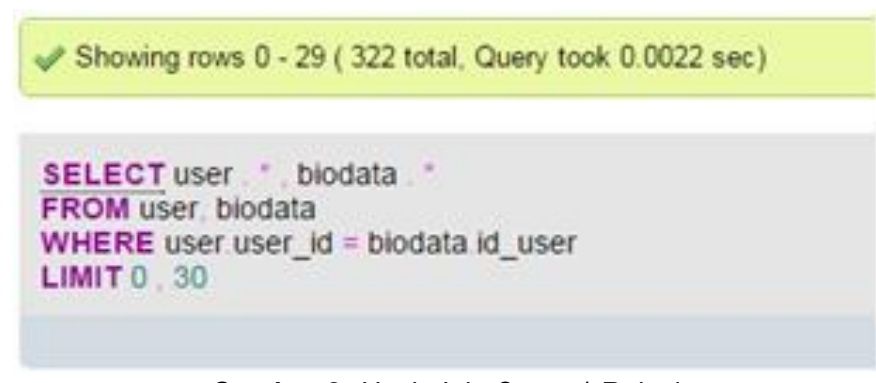

Gambar 2. Hash Join Query 1 Relasi

Pada hasil proses hash join query eksekusi 1 relasi 2 tabel dengan jumlah 322 record didapat proses waktu yang dibutuhkan untuk menampilkan data 0.0022 detik/second seperti pada gambar 2.

Inner Join Query

Showing rows $0-29$ ( 322 total, Query took $0.0028 \mathrm{sec}$ )

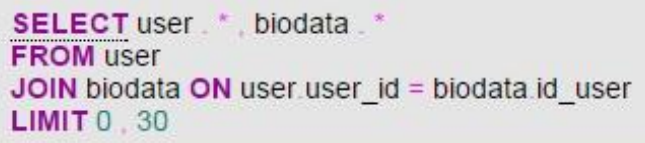

Gambar 3. Inner Join Query 1 Relasi

Hasil proses Inner Join Query eksekusi 1 relasi 2 tabel dengan jumlah 322 record didapat proses waktu lebih lama yang dibutuhkan untuk menampilkan data 0.0028 detik/second seperti hasil pada gambar 3.

b) Query 2 Relasi

Menggunakan 3 (tiga) tabel yaitu tabel user, biodata, keluarga yang saling berhubungan antar tabel 
Hash Join Query

Show query box
Showing rows $0-29$ ( 322 total, Query took $0.0030 \mathrm{sec})$
SELECT user * biodata * keluarga
FROM user, biodata, keluarga
WHERE user user_id = biodata id_user
AND user user_id = keluarga id_user
LIMIT 0,30

Gambar 4. Hash Join Query 2 Relasi

Pada hasil proses hash join query eksekusi 2 relasi 3 tabel dengan jumlah 322 record didapat proses waktu yang dibutuhkan untuk menampilkan data 0.0030 detik/second jika dibandingkan dengan 2 tabel menghasilkan selisih waktu proses seperti pada gambar 4 .

Inner Join Query

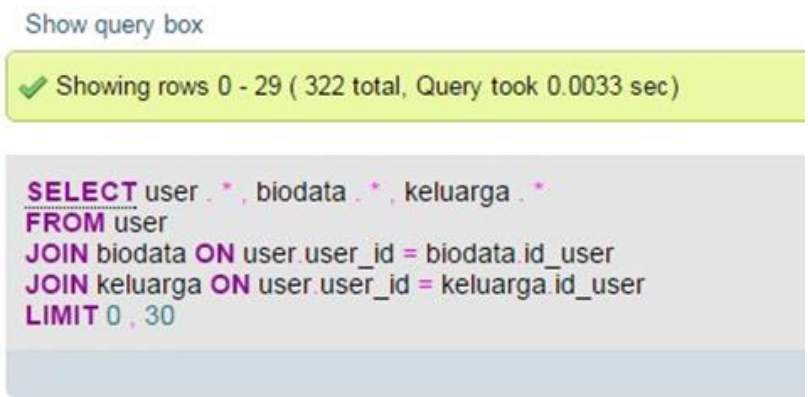

Gambar 5. Inner Join Query 2 Relasi

Hasil proses Inner Join Query eksekusi 2 relasi 3 tabel dengan jumlah 322 record didapat proses waktu lebih lama dengan sebelumnya yang membutuhkan waktu proses menampilkan data 0.0033 detik/second seperti hasil pada gambar 5 .

c) Query 3 Relasi

Menggunakan 4 (empat) tabel yaitu tabel user, biodata, keluarga dan prodi yang saling berhubungan antar tabel

Hash Join Query

Show query box

Showing rows $0-29$ ( 322 total, Query took $0.0032 \mathrm{sec}$ )

SELECT user * biodata * keluarga * prodi

FROM user biodata keluarga prodi

WHERE user_user_id = biodata id user

AND user user_id = keluarga id_user

AND biodata id_prodi $=$ prodi prodi_id

LIMIT 0,30

Gambar 6. Hash Join Query 3 Relasi

Pada hasil proses hash join query eksekusi 3 relasi 4 tabel dengan jumlah 322 record didapat proses waktu yang dibutuhkan untuk menampilkan data 0.0032 detik/second jika dibandingkan dengan 3 tabel menghasilkan selisih waktu proses seperti pada gambar 6 .

Inner Join Query 
Show query box

Showing rows 0 - 29 ( 322 total, Query took $0.0041 \mathrm{sec}$ )

SELECT user * , biodata * , keluarga * prodi

FROM user

JOIN biodata ON user user_id = biodata id_user

JOIN keluarga ON user user id = keluarga id user

JOIN prodi ON biodata id_prodi $=$ prodi.prodi_id

LIMIT 0,30

Gambar 7. Inner Join Query 3 Relasi

Hasil proses Inner Join Query eksekusi 3 relasi 4 tabel dengan jumlah 322 record didapat proses waktu lebih lama dengan sebelumnya yang membutuhkan waktu proses menampilkan data 0.0041 detik/second seperti hasil pada gambar 7 .

\section{Kesimpulan}

Penggunaan query begitu penting dalam pengelolaan Database Managenent System (DBMS) yang menghubungkan setiap tabel yang tersimpan didalam sebuah database. Karena banyaknya bentuk query yang bisa digunakan sebagai alternative untuk mencari query yang efektif dan efisien dalam setiap mengambilan data relasinya, maka dapat mengetahui query apa yang efektif dalam aplikasi kita. Kecepatan query sangat tergantung dari kondisi seperti server, kecepatan jaringan struktur database, perangkat, keras/hardware, dan juga sistem operasi. Adapun hasil dari pengujian dua query pada penelitian ini adalah sebagai berikut didapat bahwa dari setiap pengujian query, bahwa hash join query mencatat jumlah waktu lebih cepat saat record data berjumlah 1322 data, atau dengan jumlah data yang lebih banyak. Perhitungan waktu atau kecepatan query pada web browser cenderung berubah pada setiap sesi pengujian, namun tidak mengubah posisi query tercepat dan terlama waktu aksesnya.

\section{Referensi}

[1] J. Teknovasi, J. Sinuraya, M. Zarlis, E. B. Nababan, and H. Join, "Perbandingan Pencarian Data Menggunakan," vol. 01, pp. 71-93, 2014.

[2] T. Hastono, "Optimasi Query Sistem Informasi Menggunakan Stored Procedure," J. Din. Inform., vol. 8, no. 2, pp. 79-89, 2019.

[3] E. Helmud, "Optimasi Basis Data Oracle Menggunakan Complex View Studi Kasus : Pt. Berkat Optimis Sejahtera (Pt.Bos) Pangkalpinan," J. Inform., vol. 7, no. 1, pp. 80-86, 2021.

[4] M. M. Dewi and N. Rezeki, "Analisis Perbandingan Optimasi Query Nasted Join dan Hash Join pada MySQL Server," CSRID (Computer Sci. Res. Its Dev. Journal), vol. 9, no. 1, p. 31, 2017, doi: 10.22303/csrid.9.1.2017.31-42.

[5] F. Rochman, "Analisis Perbandingan Cartesian Product, Cross Join, Inner Join dan Outer Join dalam Si Akad," Techno (Jurnal Fak. Tek. Univ. Muhammadiyah Purwokerto), vol. 19, no. 1, p. 37, 2018, doi: 10.30595/techno.v19i1.2184.

[6] N. Fajaryati, T. Sukardiyono, A. Dwi, W. Utami, S. Pambudi, and B. Destiana, "Studi Penelusuran ( Tracer Study ) Terhadap Alumni Program Studi Pendidikan Teknik Informatika Jurusan," J. Electron. Informatics, Vocat. Educ., vol. 1, no. November, pp. 231-248, 2015. 